\title{
k-13. Study on the Operative Treatment for a Groupe of Sequelae after Brain Injury
}

\author{
Shigeo Watanabe, Kazuo Miwa and Shigeyuki Kobayashi \\ Kenichiro Sugita \\ Department of Neurological Surgery, Central General Hospital of \\ Health Insurance
}

Now, it has been very increased the traffic accidents by automobile, day by day, in Japan. Above all, Cerebral and Spinal damages will be counted about $70 \%$ over in these cases.

If it shall be use with good medicine for restoration of cerebral function, the sequelae of cerebral trauma will be decrease remarkably.

As shown in Table 1, have been reported in Previous papers.

Table 1. (Medicine for Restoration of Brain Function)

1) Vitamin complex ( $\mathrm{VB}_{1}, \mathrm{VB}_{2}, \mathrm{VB}_{6}, \mathrm{VB}_{12}$, F.A.D.)

2) Cytochrom C, Solcoceryl

3) A. T.P.

4) $\operatorname{Co} Q=$ Coenzyme $Q$

5) Corticosteroidal hormone

6) GABA, GABOB

7) C. D. P. - Cholin

8) Amino acids

9) Chlorophyll a

10) Brain electrolyte etc.

In Table 2 is shown the breakdown of the manifestations in 135 cases employed in the present study and who had neural manifestations after head injuries.

Table 2. (Neuropathy of Sequale)

1) Disturbance of movement of extremities . . . . . . . . . 20 cases

2) Disturbance of visuality $\ldots \ldots \ldots \ldots \ldots \ldots \ldots \ldots \ldots$ cases

3) Disturbance of speech $\ldots \ldots \ldots \ldots \ldots \ldots \ldots \ldots$ cases

4) Headache (severe or paroxysmal) $\ldots \ldots \ldots \ldots \ldots \ldots \ldots$ cases

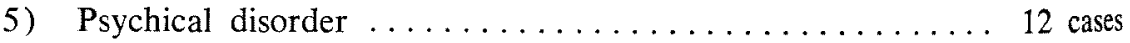

6) Epileptic attach $\ldots \ldots \ldots \ldots \ldots \ldots \ldots \ldots \ldots \ldots \ldots \ldots \ldots$ cases

7) Involantaly movements $\ldots \ldots \ldots \ldots \ldots \ldots \ldots \ldots \ldots$ cases

8) Disorders of intelligence $\ldots \ldots \ldots \ldots \ldots \ldots \ldots \ldots \ldots \ldots$ cases

Total ........................... 135 cases

For these cases we have treated neurosurgical operations, as follow:

Table 3. (Method of operation)

1) Cerebral Cicatricectomy, separation of

Cortico-dural adhesion ................... 28 cases

2) Cerebral Cicatricectomy with skull or dural 
plastic operation $\ldots \ldots \ldots \ldots \ldots \ldots \ldots \ldots \ldots \ldots \ldots$ cases

3) Resection of Epileptogenic focus

(Cortico-graphic research) $\ldots \ldots \ldots \ldots \ldots \ldots \ldots \ldots$ cases

4) Removal of chronic subdural hematoma . . . . . . . 16 cases

5) Skull and Dura plastic or Transplantation

with cortical Irrigation $\ldots \ldots \ldots \ldots \ldots \ldots \ldots \ldots \ldots$ cases

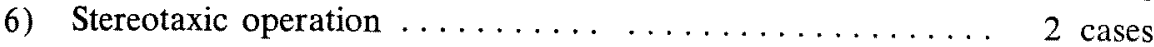

7) Hemispherectomy $\ldots \ldots \ldots \ldots \ldots \ldots \ldots \ldots \ldots \ldots \ldots \ldots \ldots$ cases

After operation, treated various physical rehabilitation by doctors, nurses, families and therapists.

Results of these neurosurgical treatments are shown in Table 4:

Table 4. (Result of operation)

1) Markedly effective $\ldots \ldots \ldots \ldots \ldots \ldots \ldots \ldots \ldots \ldots$

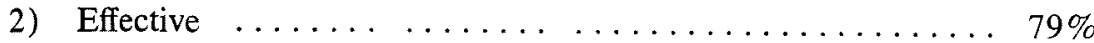

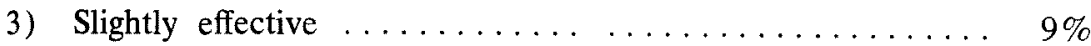

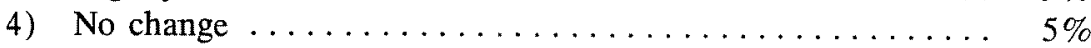

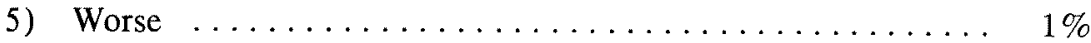

\title{
k-14. Studies on Propriocepto-spinal Reflexes with special Regards to Body Equilibrium
}

\author{
-Some Observations on Deviation in Stepping due to Lesion \\ in Cervical Soft Tissues with or without Neck Fixation- \\ Nobuya UsHio and Yutaka TADA \\ Department of Otorhinolaryngology, Tokushima Municipal Hospital \\ Manabi Hinoki, Sonoji Hine and Yoshio IsHida \\ Department of Otorhinolaryngology, School of Medicine, Tokushima University
}

The aim of this experiment is to elucidate what kinds of reflexes can be originated from the cervical proprioceptors in regards to body equilibrium.

In order to reduce abnormal excitability as well as to correct imbalance of excitability of the cervical soft tissues, fixation of the neck with a brace (polyneck) was made for vertigo cases with unilateral neck soreness and tenderness. Equilibrial tests including tests of righting reflex (Mann's test), of drift reaction (Stepping test), and of oculomotor system (Test optic nystagmus) were carried out before, and during neck fixation respectively. The following facts were noted:

1) Unilateral neck soreness and tenderness were much relieved of when the neck brace was applied.

2) Improvement of both righting function and optic equilibrial ability was simultaneously restored. It should be noted that with the neck fixation, patients 